\title{
The German Middleway as Precursor for Single Embryo Transfer. A Retrospective Data-analysis of the Düsseldorf University Hospital's Interdisciplinary Fertility Centre - UniKiD
}

\author{
Ebnet der DMW den Weg zum Single Embryo Transfer? Eine retrospektive Datenerhebung \\ des universitären interdisziplinären Kinderwunschzentrums Düsseldorf - UniKiD
}

Authors

Affiliations
T. K. Kliebisch ${ }^{1}$, A. P. Bielfeld ${ }^{2}$, J. S. Krüssel ${ }^{2}$, D. M. Baston-Büst ${ }^{2}$

1 Medical Research School der Medizinischen Fakultät der Heinrich-Heine-Universität, Düsseldorf

${ }^{2}$ Medical Center University of Düsseldorf, Dept. of OB/GYN/REI, Düsseldorf
Key words
- ART
- German Middleway
- embryo protection act
- blastocyst
Schlüsselwörter
- ART
- Deutscher Mittelweg
- ESchG
- Blastozyste

Deutsche Version unter: http://dx.doi.org/ $10.1055 / \mathrm{s}-0042-105747$

received 4.1.2016

revised $\quad 9.3 .2016$

accepted 29.3.2016

Bibliography

Dol http://dx.doi.org/

$10.1055 / \mathrm{s}-0042-105747$

Geburtsh Frauenheilk 2016; 76 :

690-698 @ Georg Thieme

Verlag KG Stuttgart · New York . ISSN 0016-5751

\section{Correspondence}

\section{Dunja Maria Baston-Büst}

Universitätsklinikum der

Heinrich-Heine-Universität

Frauenklinik

Universitäres interdisziplinäres

Kinderwunschzentrum

Düsseldorf (UniKiD)

Moorenstraße 5

40225 Düsseldorf

baston-buest@unikid.de

\section{Abstract \\ $\nabla$}

Introduction: Patients receiving fertility treatment in Germany appear to be disadvantaged in comparison to those in other countries due to the restrictive Embryo Protection Act ("Embryonenschutzgesetz, ESchG"), which prohibits the selection of a "top" embryo. The so-called German Middleway ("Deutscher Mittelweg, DMW") now provides for a liberal interpretation of the ESchG by allowing the culture of numerous pronuclear stages (2PN stage).

Materials and Methods: Retrospective cohort study of 2 assisted reproduction treatment cycles in $n=400$ patients between the ages of 21 and 45 years, either treated $2 \times$ conservatively or $1 \times$ conservatively and $1 \times$ liberally according to DMW. Results: Pregnancy was achieved in 35\% of patients in the DMW group and $31 \%$ of controls. The birth rate among controls was $28.5 \%$ and $30.5 \%$ in the DMW group. Most pregnancies resulted from the culture of $4 \times 2 \mathrm{PN}$ stages.

Conclusion: Patients in the DMW group had significantly higher pregnancy and birth rates compared to their previous cycles despite significantly increased age and significantly fewer transferred embryos. Key factors were the number of 2PNs generated and the quality of embryos transferred. Thus it can be assumed that particularly older patients with adequate ovarian reserves will benefit from DMW, i.e. the transfer of fewer embryos of the best possible quality.

\section{Zusammenfassung \\ $\nabla$}

Einleitung: Deutsche Kinderwunschpatienten erscheinen im internationalen Vergleich aufgrund der restriktiven Vorgaben des Embryonenschutzgesetzes (ESchG) und des Verbots der Auswahl eines „Top-Embryos“ benachteiligt. Die Durchführung des Deutschen Mittelwegs (DMW) erlaubt nun eine liberale Interpretation des ESchG im Sinne der Kultur mehrerer Vorkernstadien (2PN-Stadien).

Material und Methoden: Retrospektive Kohortenstudie mit 2 Behandlungszyklen im Rahmen einer assistierten Reproduktion mit $n=400 \mathrm{~Pa}$ tientinnen im Alter zwischen 21 und 45 Jahren, die entweder $2 \times$ konservativ oder $1 \times$ konservativ und $1 \times$ liberal nach DMW behandelt wurden.

Ergebnisse: Eine Schwangerschaft konnte in der DMW-Gruppe in 35\% der Fälle, in der Kontrollgruppe in $31 \%$ erzielt werden. Die Geburtenrate lag in der Kontrollgruppe bei $28,5 \%$ und in der DMW-Gruppe bei 30,5\%. Die meisten Schwangerschaften resultierten aus der Kultur von $4 \times 2 \mathrm{PN}$ Stadien.

Schlussfolgerung: Im Vergleich zum Vorzyklus einer Patientin der DMW-Gruppe kam es zu signifikant höheren Schwangerschafts- und Geburtenraten bei gleichzeitig signifikant gestiegenem Alter und signifikant weniger transferierten Embryonen. Entscheidende Einflussfaktoren waren die Anzahl der generierten 2PN-Stadien und die Qualität der transferierten Embryonen. Somit ist davon auszugehen, dass gerade ältere Patientinnen mit einer ausreichenden ovariellen Reserve vom DMW bzw. vom Transfer von weniger Embryonen mit möglichst hoher Qualität profitieren. 


\section{Introduction}

\section{$\nabla$}

Approximately $10 \%$ of couples of reproductive age are affected by involuntary childlessness [1]. Reproductive medicine in Germany is more strictly regulated than other countries in Europe and worldwide in terms of exploring new fertility treatment methods through national statutory framework conditions such as the Embryo Protection Act (ESchG) and some regional medical council professional codes of conduct. In other countries such as Belgium and Sweden elective single embryo transfer (eSET), where a single embryo is selected from those generated in a particular stimulation cycle and reimplanted, is legally sanctioned and in fact regarded as desirable by the health sector [2].

The 1990 German ESchG does not allow stock fertilisation, avoiding the regular production of surplus embryos [3]. Thus in Germany, during a single treatment cycle not all harvested ova are cultured, but rather, in the southern provinces since approx. 2008/2009 the so-called German Middleway (DMW) has been performed whereby, according to the couples wishes, as many ova as necessary are cultivated beyond the 2 pronuclear stage (2PN stage) to enable identification of 2 viable embryos for selection [4]. Many reproductive medicine centres still cultivate according to the classical so-called "rule of three", which allows a maximum of $3 \times 2 \mathrm{PN}$ stages, since no more than 3 embryos are allowed to be transferred per cycle [3]. From the legal perspective, despite this liberal interpretation of the ESchG, conditions are not the same in Germany as in many neighbouring European countries where doctors often cultivate all fertilised ova for subsequent targeted selection of a single, optimally developed embryo for transfer. Through the selection of a best or "top" embryo in most cases surplus embryos are produced, meaning that this so-called elective Single Embryo Transfer (eSET) is not permitted in Germany [5]. This situation is the result of the 1991 ESchG, which stipulates that in order to avoid surplus embryos no stock fertilisation is permissible [3]. Current data however clearly show that only 1-2 viable embryos are produced on culture of up to $6 \times 2$ PNs in $85 \%$ of observed stimulation cycles, indicating that the concern surrounding embryo stockpiling may be exaggerated [6].

When one considers the three most important criteria for pregnancy occurrence, i.e. patient age, number of transferred embryos and the embryo "quality"/viability, it is apparent that German fertility practitioners only achieve good pregnancy rates through transferring multiple embryos, which carries the risk of multiple pregnancy.

The annual report of the German IVF Register (DIR) from 2013 showed that this risk is particularly high among 30-34 year olds following transfer of two embryos: between 2000 and 2012 $20.1 \%$ of births in this group were twins and $0.41 \%$ triplets [7]. The DMW (so-called German Middleway) attempts to improve treatment results in Germany through a liberal interpretation of the ESchG which, after in vitro culture of numerous embryos and selection of those with the greatest potential viability, allows transfer at the latest at the blastocyst stage possibly even as a single embryo transfer depending on circumstances.

This article outlines to what extent the DMV differs from standard artificial insemination cycles, and whether its introduction at the UniKiD in 2011 has lead to significantly higher pregnancy rates, fewer multiple pregnancies and consequently significant reductions in health and financial burdens of treated couples. We pay particular attention to the question of which patient groups are able to benefit from DMW, in other words, which management algorithms predict success with this method. This is especially important to clarify whether DMW, as implemented in UniKiD and most other centres in Nordrhein as well as in many centres in other regional medical council areas, will pave the way towards Single Embryo Transfer.

\section{Materials and Methods \\ $\nabla$}

\section{Procedure description}

The indication for reproductive medical treatment (in vitro fertilisation [IVF] or intracytoplasmic sperm injection [ICSI]) was made after comprehensive history taking from the couple, gynaecological examination and measurement of relevant hormonal levels in the women and complete andrological work-up of the male partner. The couples were counselled on the treatment procedure including relevant risks and possible complications. Thereafter medical pre-treatment was commenced with either a short/long agonist protocol or an antagonist protocol with hCG application for ovulation induction and oocyte puncture. After fertilisation with IVF or ICSI, in the conservative ART cycle (control group) a maximum of $3 \times 2$ PN stages was cultured for $2-3$ days up until transfer, while in the DMW cycle a maximum of $6 \times 2$ PN stages was selected for 2-5 day in vitro culture.

\section{Inclusion and exclusion criteria}

400 patients between the ages of 21 and 45 years who received assisted reproduction (IVF or ICSI) at least twice between 2006 and 2013 were included in this retrospective cohort study and were allocated to either control $(n=200, C G)$ or experimental groups $(n=200, E G)$. A further inclusion requirement was that the observed treatment cycle was not discontinued. The two last treatments were taken into account $(1 \mathrm{st}$ cycle $=$ CG1, 2nd cycle = CG2 vs. 1st cycle = EG1 and 2nd cycle EG2 [EG2 hereafter denoted as DMW]). We excluded patients who were only treated according to the DMW, which lead to many patients not automatically entering the analysis especially between 2011 and 2013.

Inclusion criteria for the EG were at least one standard protocol treatment (EG1) and one treatment according to the DMW (DMW). Inclusion criteria for the CG were at least two standard treatment cycles (CG1 and CG2). Through matching the groups in this way it was not only possible to compare CG vs. EG, but also to perform a patient-internal analysis by comparing previous with subsequent cycles in individual patients.

As an example, in a patient in the EG group who was treated four times, twice with each protocol, only the last standard cycle and last DMW cycle were recorded and analysed with all parameters. In CG patients the last two standard cycles were captured. This method was chosen in order to avoid positive selection bias within the collective and to enable uniform analysis of patients with different numbers of treatment cycles.

\section{Parameters}

The following parameters were captured: Patient age, number of years trying to fall pregnant, body mass index (BMI), number of previous live births, abortions and evacuations, partner's andrological results, method of insemination (IVF or ICSI), date of puncture and embryo transfer, and protocol type. 
Additional parameters measured:

- Base-line hormone levels between day 3 and 5 of the cycle:

- Luteinising hormone (LH)

- Follicle-stimulating hormone (FSH)

- Anti-Müllerian hormone (AMH)

- Thyroid stimulating hormone (TSH)

- Testosterone

- Prolactin

- Dehydroepiandrosterone sulphate (DHEA-S)

- LH/FSH ratio (calculated)

- On the day of human chorionic gonadotropin (hCG) application for ovulation induction:

- Oestradiol $\left(\mathrm{E}_{2}\right)$ and

- Luteinising hormone (LH)

Also documented and analysed:

- Medication for stimulation:

- Recombinant follicle-stimulating hormone ( $\mathrm{rFSH})$

- Recombinant luteinising hormone (rLH)

- HMG

- Recombinant human chorionic gonadotropin (rhCG)

Corifollitropin alfa

$\checkmark$ HCG

- Gonadotropin-releasing hormone agonists (GnRH agonists)

- Gonadotropin-releasing hormone antagonists (GnRH antagonists)

- Contraceptive in the previous cycle (if applicable)

- Thyroid hormone substitution (if applicable)

- Anticoagulants (if applicable)

Further parameters analysed included: the number of punctured oocytes and their quality through the course of treatment (defective oocytes, germinal vesicles [GV], 1st meiotic division attained [MI], mature oocytes ["nachgereift" = N], 2nd meiotic division attained [MII] and following insemination [2PN]), the numbers of cryopreserved 2PNs, cultured 2PNs, planned and transferred embryos, and the quality of embryos (embryo grading). The first hCG value was obtained 13 days after oocyte puncture, the second a further 7 days later. Also captured were the first ultrasound result, possible twin constellation with its peculiarities such as vanishing twins, and lastly data on the birth (duration of pregnancy, sex, weight and abnormalities of the newborn, type of delivery). Parameters captured on history included: treatment outside of our centre, discontinued treatments in the past and reasons in each case (ovarian hyperstimulation syndrome [OHSS], no 2PNs); number of cycles with optimally timed sexual intercourse (“Geschlechtsverkehr zum Optimalen Zeitpunkt”, VZO), number of intrauterine inseminations (IUI), in vitro fertilisations (IVF), intracytoplasmic sperm injections (ICSI) and cryotransfers; demographic factors such as marital status and nicotine consumption; gynaecological treatments such as laparoscopy (LSK), hysteroscopy (HSK), chromopertubation; gynaecological diseases such as endometriosis, uterine myomas, polycystic ovarian syndrome (PCO) and uterine position.

\section{Statistical analysis}

All calculations, statistical and descriptive analyses for this study were conducted using the IBM SPSS Statistics Version 22.0.0.0 and with support and specialist expertise from .05 Statistikberatung Düsseldorf.

Statistical analysis was by means of the t-test and Levene's test (comparison of means), as well as Pearson's $X^{2}$-test, the MannWhitney and Wilcoxon tests (group analyses) and ANOVA analyses (linear regression analyses)/the Omnibus test (logistic regres- sion analyses). Correlation analyses were also performed. Statistical significance was defined as $\mathrm{p}<0.05$.

\section{Results}

Statistical description of primary outcome measures

Primary outcomes were pregnancy rate (pregnancy progressing with rising hCG and positive results on 1st ultrasound), birth rate (birth of one or more children) and absolute number of children born/live births.

In the CG1 pregnancy was achieved in $18 \%$ of cases (1st hCG $\bar{x}$ [average] $=152 \mathrm{mU} / \mathrm{ml}, 2$ d hCG $\overline{\mathrm{x}}=2373 \mathrm{mU} / \mathrm{ml}, \mathrm{n}=36$ ), in EG1 in $16.5 \%$ (1st hCG $\bar{x}=86 \mathrm{mU} / \mathrm{ml}$, 2nd hCG $\bar{x}=1384 \mathrm{mU} / \mathrm{ml}$, $\mathrm{n}=33$ ), in CG2 in $31 \%$ ( $1 \mathrm{st}$ hCG $\overline{\mathrm{x}}=146 \mathrm{mU} / \mathrm{ml}$, 2nd hCG $\overline{\mathrm{x}}=2366 \mathrm{mU} / \mathrm{ml}, \mathrm{n}=62$ ) and in the DMW group in $35 \%$ of cases (1st hCG $\overline{\mathrm{x}}=222 \mathrm{mU} / \mathrm{ml}, 2$ nd hCG $\overline{\mathrm{x}}=2530 \mathrm{mU} / \mathrm{ml}, \mathrm{n}=70$ ).

In CG1 the birth rate of 5.5\% ( 11 of $n=200$ ) was equal to the number of children born, and in EG1 was $5 \%$ ( 10 of $n=200)$. The birth rate in CG2 was $28.5 \%$ (57 of $\mathrm{n}=200$ ) with 66 the absolute number of children born. The birth rate in the DMW group was $30.5 \%$ (61 of $n=200$ ), 75 the absolute number of children born.

The primary outcomes are shown in 0 Fig. $\mathbf{1} \mathbf{a}$ and $\mathbf{b}$. Only patients who achieved a progressing pregnancy in the first or second cycles were included in the analysis. Purely biochemical pregnancies were not included.

Group similarity and unchanged parameters CG vs. EG These parameters refer to the end of the data collection period and are therefore not specific for individual patient treatment cycles. Only CG and EG are differentiated in order to reflect the similarity of the groups.

It was found that the CG and EG were not significantly different with respect to total number of ART cycles (IVF and ICSI), VZO, IUIs, number of cryotransfers, smoking habit, occurrence of OHSS, absent 2PN cells, discontinued treatments, marital status, incidence of endometriosis, HSKs, chromopertubations, presence of uterine myomas, uterus position or history of PCO.

There were however significant differences between the groups in the number of DMW cycles $(E G=1.44 \pm 0.77, p=0.000$ ), since only the EG underwent DMW, and in the number of cryotransfers $(\mathrm{CG}=1.05 \pm 1.39, \mathrm{EG}=1.61 \pm 1.82, \mathrm{p}=0.001)$ and history of LSKs (CG $=30.5 \%, E G=40 \%, p=0.047)$.

\section{Group similarity and comparison of first cycle CG1 vs. EG1}

For the first cycle both groups were treated according to the standard protocol and here too the similarity of the groups was shown. The groups did not differ significantly with respect to: age; BMI; $E_{2}$ and LH levels on hCG application; use of rFSH, rFSH $+\mathrm{rLH}, \mathrm{GnRH}$ agonists and antagonists; laboratory parameters (LH/FSH, AMH, TSH, testosterone, LH, DHEA); number of oocytes MI; cultivated 2PNs; transferred and cultivated embryos; 2nd hCG; day between puncture and transfer, and days from transfer to birth; quality of the first, second and third embryos; 1st ultrasound result, pregnancy and birth rates or number of live births. The groups did differ significantly for: dose of FSH $(\mathrm{CG}=2509 \pm 1357 \mathrm{IU}, \mathrm{EG}=2070 \pm 1058 \mathrm{IU}, \mathrm{p}=0.0003)$, prolactin level $(\mathrm{CG}=14.52 \pm 7.34, \mathrm{EG}=16.18 \pm 7.54, \mathrm{p}=0.031)$, FSH level ( $C G=8.32 \pm 4.14$, EG $=7.24 \pm 3.48, p=0.006)$, number of punctured oocytes ( $C G=7.75 \pm 3.82, E G=9.12 \pm 4.05, p=0.001)$, MII oocytes $\quad(C G=6.02 \pm 3.38, \quad E G=7.21 \pm 3.60, \quad p=0.001), \quad 2 P N s$ 


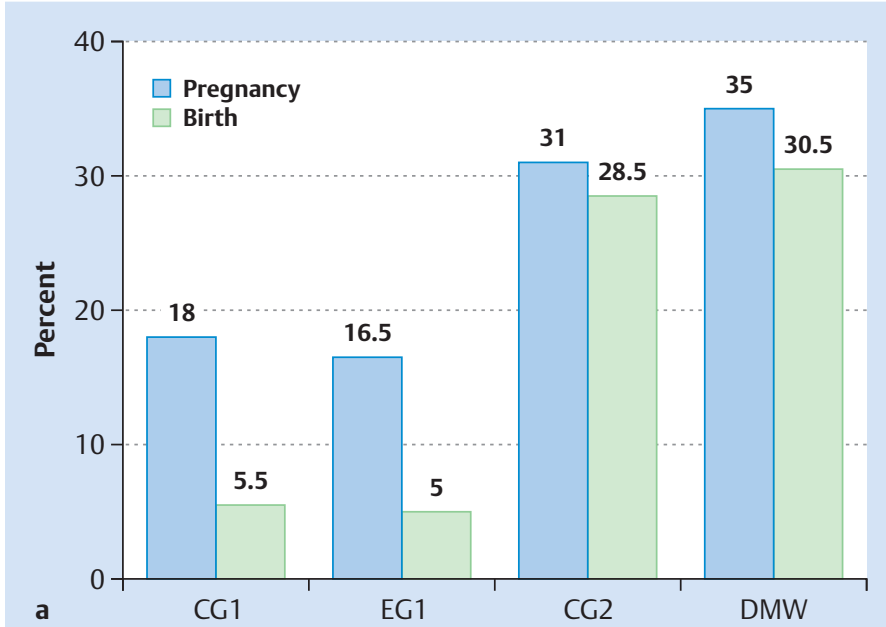

Fig. $\mathbf{a}$ and $\mathbf{b}$ a Pregnancy and birth rates within the study collectives. Representation of the pregnancy and birth rates of the control group (CG1 and 2, the first and last conservative cycles respectively) and the experimental group (EG1 initial conservative schema, then DMW).

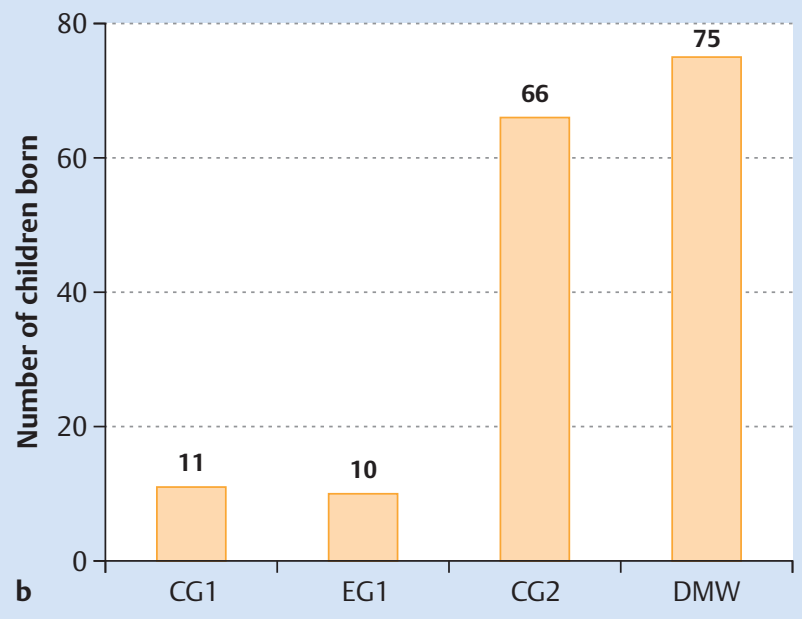

b Number of live births in the treatment groups. The greatest number of children were born following treatment according to the DMW schema followed by conservative treatment.
( $\mathrm{CG}=3.77 \pm 2.47, \mathrm{EG}=4.88 \pm 2.88, \mathrm{p}=0.001)$, cryopreserved 2PNs $(\mathrm{CG}=1.40 \pm 2.20, \quad \mathrm{EG}=2.46 \pm 2.91, \mathrm{p}=0.000), \quad 1 \mathrm{st} \quad \mathrm{hCG} \quad(\mathrm{CG}=$ $151.58 \pm 181.95, E G=83.43 \pm 59.86, p=0.046)$ and type of ART $(\mathrm{CG}=88.5 \%$ ICSI, EG $=80 \%$ ICSI, $\mathrm{p}=0.020$ ).

\section{Comparison of groups and second cycle \\ CG2 vs. EG2 (DMW)}

There were no significant differences in the primary outcomes, although higher pregnancy rates $(+4 \%)$, birth rates $(+2 \%)$ and more live births $(+9)$ were achieved in the DMW despite fewer embryos transferred $(C G=1.96 \pm 0.62, E G=1.83 \pm 0.38, p=0.009)$ (- Table 1).

\section{Group comparison and 1 st and 2 nd cycles}

\section{EG1 vs. EG2 (DMW) in individual patients}

Since this comparison considered different cycles within the same individuals, one standard (EG1) and one DMW (EG2) protocol, it was possible to show that patients benefitted significantly from the new method despite their inevitably significantly increased age $(E G 1=35.43 \pm 3.99, \quad E G 2=36.45 \pm 3.86, p=0.000)$. Significantly higher pregnancy rates $(+18.5 \%)$ and birth rates $(+25.5 \%)$ were achieved despite significantly fewer embryos being transferred $(E G 1=1.97 \pm 0.46, E G 2=1.83 \pm 0.38, \mathrm{p}=0.000)$ ( Table 2).

\section{Regression analyses of EG1, CG2 and EG2 (DMW)}

\section{Effect of embryo quality on pregnancy occurrence}

A multiple logistic regression was also performed with the quality (A to C) of the first, second and third transferred embryo as predictors of pregnancy occurrence.

For EG1 the overall variance of the logistic regression was $X^{2}(6)=19.9, p<0.01$. The quality of the second embryo was a significant predictor $(\mathrm{p}<0.05)$.

For CG2 the overall variance of the logistic regression was $X^{2}(6)=28.13, p<0.01$ with the quality of the first and second embryos being significant $(\mathrm{p}<0.01)$. No significant correlation was found for EG2.
Effect of ultrasound results on occurrence of birth In EG1 ( $\left.X^{2}[3]=106.77, p<0.01\right), C G 2\left(X^{2}[3]=190.67, p<0.01\right)$ and EG2 $\left(X^{2}[3]=178.77, p<0.01\right)$ the first ultrasound result was a significant predictor of a birth.

\section{Regression analysis EG2 (DMW) \\ Effect of cultivated 2PN stages and patient age} on number of blastocysts generated

The overall variance of the multiple linear regression was $\mathrm{R}^{2}=0.25(\mathrm{~F}=32.67, \mathrm{p}<0.01)$. The number of cultured 2PN cells $(\beta=0.49, p<0.01)$ was a significant predictor.

\section{Effect of number of cultivated 2PN stages}

on the first ultrasound result at 7 weeks gestation Overall, in CG2 23\% achieved intact singleton pregnancies. $2.5 \%$ occurred after culture of $1,14 \%$ after culture of 2 , and $6.5 \%$ on culture of $3 \times 2$ PNs. $6.5 \%$ had intact twin pregnancies with $6 \%$ occurring after culture of 2 , and $0.5 \%$ on culture of $3 \times 2 \mathrm{PN}$ stages. In EG2 $24.5 \%$ of cases had a singleton pregnancy with $1 \%$ occurring after culture of $1,2 \%$ after $2,2.5 \%$ after $3,7.5 \%$ after $4,7 \%$ after 5 and $4.5 \%$ after culture of 6 2PNs. Twin pregnancies ( $8 \%$ ) occurred in $0.5 \%$ after culture of $2,6.5 \%$ after 4 and $0.5 \%$ after culture of both 5 and $6 \times 2$ PNs respectively ( Table 3 ).

\section{Discussion \\ $\nabla$}

The introduction of the DMW is a further step towards increasing the pregnancy rate with ART despite restrictive German legislation. We have shown that these patients can benefit significantly from new techniques: in comparison to previous treatment cycles, significantly higher pregnancy and birth rates were attained despite patents being significantly older and receiving significantly fewer transferred embryos. It was clearly demonstrated that ultimately the number of generated 2PN stages and the quality of transferred embryos were decisive.

Due to more embryos being cultivated, the number of transferred embryos could be reduced while achieving higher pregnancy and 
Table 1 Demographics and descriptive statistics by number of patients ( $\mathrm{n}$ ) for DMW group vs. conservative treatment (CG2). Representation of mean values \pm standard deviations or percentages; in brackets absolute incidences with $p<0.05$.

\begin{tabular}{|c|c|c|c|}
\hline & $\operatorname{CG} 2(n=200)$ & DMW $(n=200)$ & p-value \\
\hline Age & $36.94 \pm 4.03(200)$ & $36.45 \pm 3.86(200)$ & \\
\hline BMI & $23.39 \pm 4.01(199)$ & $22.88 \pm 3.91(200)$ & \\
\hline $\mathrm{E}_{2}$ at hCG application in $\mathrm{pg} / \mathrm{ml}$ & $1827 \pm 1358(200)$ & $1702 \pm 1124(200)$ & \\
\hline LH at hCG application in $\mu \mathrm{lU} / \mathrm{ml}$ & $3.90 \pm 2.84(200)$ & $3.34 \pm 3.18(200)$ & \\
\hline Total FSH dose in IU & $2505 \pm 1419(200)$ & $1987 \pm 1158(200)$ & $<0.05$ \\
\hline GnRH antagonist in $\mathrm{mg}$ & $0.52 \pm 0.76(70)$ & $0.77 \pm 0.81(103)$ & $<0.05$ \\
\hline GnRH agonist in $\mathrm{mg}$ & $4.93 \pm 4.09(128)$ & $3.30 \pm 3.70(97)$ & \\
\hline $\mathrm{LH} / \mathrm{FSH}$ ratio in $\mu \mathrm{IU} / \mathrm{ml}$ & $0.87 \pm 0.44(193)$ & $0.90 \pm 0.38(191)$ & \\
\hline $\mathrm{AMH}$ in $\mu \mathrm{g} / \mathrm{l}$ & $2.00 \pm 2.76(124)$ & $1.99 \pm 1.98(169)$ & \\
\hline $\mathrm{TSH}$ in $\mu \mathrm{IU} / \mathrm{ml}$ & $1.72 \pm 0.82(197)$ & $1.92 \pm 1.87(193)$ & \\
\hline Testosterone in $\mathrm{ng} / \mathrm{ml}$ & $0.27 \pm 0.18(195)$ & $0.25 \pm 0.16(190)$ & \\
\hline Prolactin in $\mathrm{ng} / \mathrm{ml}$ & $15.14 \pm 12.09(190)$ & $15.83 \pm 7.57(190)$ & \\
\hline $\mathrm{FSH}$ in $\mu \mathrm{IU} / \mathrm{ml}$ & $8.32 \pm 4.02(193)$ & $7.04 \pm 2.32(192)$ & $<0.05$ \\
\hline $\mathrm{LH}$ in $\mu \mathrm{IU} / \mathrm{ml}$ & $6.27 \pm 2.54(196)$ & $6.05 \pm 2.51(194)$ & \\
\hline DHEA in $\mu g / l$ & $141.24 \pm 69.87(191)$ & $151.34 \pm 70.85(192)$ & \\
\hline Number of oocytes & $7.6 \pm 4.36(200)$ & $9.89 \pm 3.96(200)$ & $<0.05$ \\
\hline Ml oocytes & $0.87 \pm 1.16(104)$ & $0.99 \pm 1.33(102)$ & \\
\hline MII oocytes & $5.84 \pm 3.59(200)$ & $7.88 \pm 3.50(200)$ & $<0.05$ \\
\hline 2PNs & $3.82 \pm 2.68(200)$ & $5.36 \pm 2.90(200)$ & $<0.05$ \\
\hline 2PNs planned for culture & $2.22 \pm 0.49(200)$ & $5.18 \pm 0.95(200)$ & $<0.05$ \\
\hline Cultivated 2PNs & $2.01 \pm 0.63(200)$ & $3.96 \pm 1.40(200)$ & $<0.05$ \\
\hline Transferred embryos & $1.96 \pm 0.62(200)$ & $1.83 \pm 0.38(200)$ & $<0.05$ \\
\hline 1st hCG in $\mathrm{mU} / \mathrm{ml}$ & $145.78 \pm 122.59(62)$ & $221.52 \pm 458.98(62)$ & \\
\hline 2nd hCG in $\mathrm{mU} / \mathrm{ml}$ & $2365.75 \pm 1740.55(62)$ & $2529.6 \pm 1915.91(62)$ & \\
\hline Difference in days between puncture and transfer & $2.31 \pm 0.46(200)$ & $3.93 \pm 1.18(200)$ & $<0.05$ \\
\hline Days between transfer and birth (duration of pregnancy) & $254.95 \pm 15.39(57)$ & $245.56 \pm 23.20(61)$ & $<0.05$ \\
\hline Quality of 1st embryo & $(200)$ & $(198)$ & $<0.05$ \\
\hline$\Rightarrow A$ & $48 \%(96)$ & $67.5 \%(135)$ & \\
\hline$>\mathrm{B}$ & $43 \%(86)$ & $22 \%(44)$ & \\
\hline$\rightarrow C$ & $9 \%(18)$ & $9.5 \%(19)$ & \\
\hline Quality of 2nd embryo & $(156)$ & $(161)$ & \\
\hline$\rightarrow A$ & $32.5 \%(64)$ & $43,5 \%(87)$ & \\
\hline$\Rightarrow$ B & $34.5 \%(69)$ & $21 \%(42)$ & \\
\hline$>\mathrm{C}$ & $11.5 \%(23)$ & $16 \%(32)$ & \\
\hline Quality of 3rd embryo & (33) & $(0)$ & $<0.05$ \\
\hline$\Rightarrow \mathrm{A}$ & $24 \%(8)$ & & \\
\hline$\Rightarrow \mathrm{B}$ & $55 \%(18)$ & & \\
\hline$\checkmark \mathrm{C}$ & $21 \%(7)$ & & \\
\hline \multicolumn{4}{|c|}{ Blastocysts (A) and morula stages $(\mathrm{C})$ are assessed in quality criteria } \\
\hline ART type (ICSI) & $92 \%(184)$ & $81.5 \%(163)$ & $<0.05$ \\
\hline - 1st US & (62) & $(70)$ & \\
\hline - Singleton & $74 \%(46)$ & $71 \%(50)$ & \\
\hline Twin & $21 \%(13)$ & $23 \%(16)$ & \\
\hline - Abortion & $5 \%(3)$ & $6 \%(4)$ & \\
\hline Pregnancy & $31 \%(62)$ & $35 \%(70)$ & \\
\hline Birth & $28.5 \%(57)$ & $30.5 \%(61)$ & \\
\hline Number of live births & 66 & 75 & \\
\hline
\end{tabular}

birth rates. In this context it was the embryo quality and not the day of transfer that was decisive. Another study has also shown that embryo quality is the most significant factor for the cumulative live birth rate in the context of eSET, although here the odds ratio in the presence of $\geq 3$ "top" embryos was 2.66 [8].

Better trophectoderm morphology, low patient age and the best possible blastocyst developmental stage had the greatest influence on clinical pregnancy and live birth rates in an American study. Thus primarily the trophectoderm morphology and blastocyst stage should be used to select the best embryo for transfer. Blastocyst stage was associated with live birth rates of $50 \%$ (hatching), 49.5\% (expanded) and 36.7\% (early) [9].
A further study also showed that age and number of "top" embryos are significantly associated with occurrence of clinical pregnancy after eSET. The authors recommend performing eSET preferably on day 3 [10].

Practice algorithms should be developed to predict success with the DMW. The number of cultivated 2PNs had a stronger influence on blastocyst extraction than age, hence it is older patients in particular who benefit from the DMW when enough oocytes can be harvested and cultivated.

It was shown that culture of $4 \times 2 \mathrm{PN}$ stages in the context of DMW resulted in the highest pregnancy rates; overall $14 \%$ of the 
Table 2 Demographics and descriptive statistics by number of patients ( $\mathrm{n}$ ) for patients undergoing the DMW method in their second cycle. Representation of mean values \pm standard deviations or percentages; in brackets absolute incidences with $p<0.05$.

\begin{tabular}{|c|c|c|c|}
\hline & EG1 & DMW & p-value \\
\hline Age & $35.43 \pm 3.99(200)$ & $36.45 \pm 3.86(200)$ & $<0.05$ \\
\hline BMI & $22.83 \pm 3.98(200)$ & $22.88 \pm 3.91(200)$ & \\
\hline $\mathrm{E}_{2}$ at $\mathrm{hCG}$ application in $\mathrm{pg} / \mathrm{ml}$ & $1976 \pm 1292(197)$ & $1702 \pm 1124(200)$ & $<0.05$ \\
\hline LH at hCG application in $\mu \mathrm{lU} / \mathrm{ml}$ & $3.91 \pm 3.50(197)$ & $3.34 \pm 3.18(200)$ & \\
\hline Total FSH dose in IU & $2070 \pm 1058(200)$ & $1987 \pm 1158(200)$ & \\
\hline GnRH antagonist & $0.44 \pm 0.70(69)$ & $0.77 \pm 0.81(103)$ & $<0.05$ \\
\hline GnRH agonist & $5.28 \pm 3.93(141)$ & $3.30 \pm 3.70(97)$ & $<0.05$ \\
\hline $\mathrm{LH} / \mathrm{FSH}$ ratio in $\mu \mathrm{lU} / \mathrm{ml}$ & $0.93 \pm 0.48(192)$ & $0.90 \pm 0.38(191)$ & \\
\hline $\mathrm{AMH}$ in $\mu \mathrm{g} / \mathrm{I}$ & $2.20 \pm 1.98(192)$ & $1.99 \pm 1.98(169)$ & $<0.05$ \\
\hline $\mathrm{TSH}$ in $\mu \mathrm{IU} / \mathrm{ml}$ & $1.87 \pm 0.98(193)$ & $1.92 \pm 1.87(193)$ & \\
\hline Testosterone in $\mathrm{ng} / \mathrm{ml}$ & $0.26 \pm 0.17(190)$ & $0.25 \pm 0.16(190)$ & $<0.05$ \\
\hline Prolactin in $\mathrm{ng} / \mathrm{ml}$ & $16.18 \pm 7.54(190)$ & $15.83 \pm 7.57(190)$ & \\
\hline $\mathrm{FSH}$ in $\mu \mathrm{IU} / \mathrm{ml}$ & $7.24 \pm 3.48(192)$ & $7.04 \pm 2.32(192)$ & \\
\hline $\mathrm{LH}$ in $\mu \mathrm{IU} / \mathrm{ml}$ & $6.41 \pm 3.97(194)$ & $6.05 \pm 2.51(194)$ & \\
\hline DHEA-S in $\mu \mathrm{g} / \mathrm{l}$ & $152.07 \pm 71.79(191)$ & $151.34 \pm 70.85(192)$ & \\
\hline Number of oocytes & $9.12 \pm 4.05(200)$ & $9.89 \pm 3.96(200)$ & $<0.05$ \\
\hline Ml oocytes & $0.85 \pm 1.17(98)$ & $0.99 \pm 1.33(102)$ & \\
\hline Mll oocytes & $7.21 \pm 3.60(197)$ & $7.88 \pm 3.50(200)$ & $<0.05$ \\
\hline 2PNs planned for culture & $2.11 \pm 0.37(200)$ & $5.18 \pm 0.95(200)$ & $<0.05$ \\
\hline Cryopreserved 2PNs & $2.46 \pm 2.91(108)$ & $1.06 \pm 2.08(53)$ & $<0.05$ \\
\hline Cultivated 2PNs & $2.03 \pm 0.49(199)$ & $3.96 \pm 1.40(200)$ & $<0.05$ \\
\hline Transferred embryos & $1.97 \pm 0.46(200)$ & $1.83 \pm 0.38(200)$ & $<0.05$ \\
\hline 1 st hCG in $\mathrm{mU} / \mathrm{ml}$ & $83.43 \pm 59.86(36)$ & $221.52 \pm 458.98(62)$ & $<0.05$ \\
\hline 2nd hCG in $\mathrm{mU} / \mathrm{ml}$ & $1513.13 \pm 1327.49(36)$ & $2529.6 \pm 1915.91(62)$ & $<0.05$ \\
\hline Difference in days between puncture and transfer & $2.35 \pm 0.48(200)$ & $3.93 \pm 1.18(200)$ & $<0.05$ \\
\hline Days between transfer and birth (duration of pregnancy) & $252,9 \pm 12,78(10)$ & $245.56 \pm 23.20(61)$ & \\
\hline Quality of 1st embryo & (200) & $(198)$ & $<0.05$ \\
\hline$\rightarrow A$ & $52 \%(104)$ & $67.5 \%(135)$ & \\
\hline$\checkmark B$ & $39.5 \%(79)$ & $22 \%(44)$ & \\
\hline$\checkmark \mathrm{C}$ & $8.5 \%(17)$ & $9.5 \%(19)$ & \\
\hline Quality of 2nd embryo & (175) & (161) & \\
\hline$\checkmark A$ & $27 \%(54)$ & $43.5 \%(87)$ & \\
\hline$>\mathrm{B}$ & $46 \%(92)$ & $21 \%(42)$ & \\
\hline - $\mathrm{C}$ & $12.5 \%(25)$ & $16 \%(32)$ & \\
\hline Quality of 3rd embryo & (20) & $(0)$ & $<0.05$ \\
\hline - A & $25 \%(5)$ & & \\
\hline$>\mathrm{B}$ & $50 \%(10)$ & & \\
\hline D $\mathrm{C}$ & $25 \%(5)$ & & \\
\hline \multicolumn{4}{|c|}{ Blastocysts (A) and morula stages (C) are assessed in quality criteria } \\
\hline ART type (ICSI) & $80 \%(160)$ & $81.5 \%(163)$ & $<0.05$ \\
\hline > 1st US & (33) & $(70)$ & \\
\hline - Singleton & $42 \%(14)$ & $71 \%(50)$ & \\
\hline - Twin & $12 \%(4)$ & $23 \%(16)$ & \\
\hline - Abortion & $46 \%(15)$ & $6 \%(4)$ & \\
\hline Pregnancy & $16.5 \%(33)$ & $35 \%(70)$ & $<0.05$ \\
\hline Birth & $5 \%(10)$ & $30.5 \%(61)$ & $<0.05$ \\
\hline Number of live births & 10 & 75 & $<0.05$ \\
\hline
\end{tabular}

$32.5 \%$ pregnancies achieved were due to the culture of $4 \times 2 \mathrm{PN}$ stages. $12.5 \%$ resulted from culture of $>4 \times 2 \mathrm{PN}$ stages.

On the one hand, the fact that culture of $4 \times 2 \mathrm{PN}$ stages achieved the highest pregnancy rates can be explained by the patients having a better prognosis. On the other hand, this possible statistical bias is put into perspective by the fact that patients with worse prognosis were also included in the group when the planned number of $6 \times 2$ PNs to be cultured was not achieved. Naturally, it must always be taken into consideration that surplus embryos will be produced in the process of culturing 2PN stages according to the DMW, and these must then be frozen. Since this rate of surplus embryos should be kept as low as possible, decisions should be made on an individual basis after careful history taking and taking previous stimulations and transfers into consideration.

A number of blood values and medications were identified as predictors: it was statistically advantageous, in terms of generating a high number of oocytes, to achieve the highest possible $\mathrm{E}_{2}$ level together with an initially high $\mathrm{AMH}$ level and the lowest possible $\mathrm{LH}$.

High doses of urofollitropin + lutropin and GnRH antagonists with resultant long stimulation were negative predictors of oocyte number. This patient collective demonstrated low AMH levels and a poor ovarian response to stimulation, which explained the long duration of stimulation using the antagonist protocol. 
Table 3 Cross tabulation. Representation of the first ultrasound result at 7 weeks gestation with respect to the number of cultivated 2PNs in CG2 and DMW.

\begin{tabular}{|c|c|c|c|c|c|c|c|c|}
\hline \multicolumn{9}{|c|}{ Number of cultivated 2PNs (2nd cycle) $\times 1$ st ultrasound (2nd cycle) } \\
\hline \multicolumn{4}{|c|}{ CG2 and DMW } & \multicolumn{4}{|c|}{ 1st ultrasound (2nd cycle) } & \multirow[t]{2}{*}{ Total } \\
\hline & & & & No ultrasound & Intact, singleton & Intact, twins & Abortion & \\
\hline \multirow[t]{8}{*}{ CG2 } & Number of cultivated 2PNs & 1 & Count & 34 & 5 & 0 & 0 & 39 \\
\hline & & & $\%$ of Total & $17.0 \%$ & $2.5 \%$ & $0.0 \%$ & $0.0 \%$ & $19.5 \%$ \\
\hline & & 2 & Count & 78 & 28 & 12 & 3 & 121 \\
\hline & & & $\%$ of Total & $39.0 \%$ & $14.0 \%$ & $6.0 \%$ & $1.5 \%$ & $60.5 \%$ \\
\hline & & 3 & Count & 26 & 13 & 1 & 0 & 40 \\
\hline & & & $\%$ of Total & $13.0 \%$ & $6.5 \%$ & $0.5 \%$ & $0.0 \%$ & $20.0 \%$ \\
\hline & Total & & Count & 138 & 46 & 13 & 3 & 200 \\
\hline & & & $\%$ of Total & $69.0 \%$ & $23.0 \%$ & $6.5 \%$ & $1.5 \%$ & $100.0 \%$ \\
\hline \multirow[t]{14}{*}{ DMW } & Number of cultivated 2PNs & 1 & Count & 7 & 2 & 0 & 0 & 9 \\
\hline & & & $\%$ of Total & $3.5 \%$ & $1.0 \%$ & $0.0 \%$ & $0.0 \%$ & $4.5 \%$ \\
\hline & & 2 & Count & 24 & 4 & 1 & 0 & 29 \\
\hline & & & $\%$ of Total & $12.0 \%$ & $2.0 \%$ & $0.5 \%$ & $0.0 \%$ & $14.5 \%$ \\
\hline & & 3 & Count & 20 & 5 & 0 & 0 & 25 \\
\hline & & & $\%$ of Total & $10.0 \%$ & $2.5 \%$ & $0.0 \%$ & $0.0 \%$ & $12.5 \%$ \\
\hline & & 4 & Count & 39 & 15 & 13 & 2 & 69 \\
\hline & & & $\%$ of Total & $19.5 \%$ & $7.5 \%$ & $6.5 \%$ & $1.0 \%$ & $34.5 \%$ \\
\hline & & 5 & Count & 19 & 14 & 1 & 0 & 34 \\
\hline & & & $\%$ of Total & $9.5 \%$ & $7.0 \%$ & $0.5 \%$ & $0.0 \%$ & $17.0 \%$ \\
\hline & & 6 & Count & 24 & 9 & 1 & 0 & 34 \\
\hline & & & $\%$ of Total & $12.0 \%$ & $4.5 \%$ & $0.5 \%$ & $0.0 \%$ & $17.0 \%$ \\
\hline & Total & & Count & 133 & 49 & 16 & 2 & 200 \\
\hline & & & $\%$ of Total & $66.5 \%$ & $24.5 \%$ & $8.0 \%$ & $1.0 \%$ & $100.0 \%$ \\
\hline
\end{tabular}

Other study groups have also demonstrated that a long agonist protocol, which constituted the majority of stimulations up until 2012 , is better suited to the production of a greater number of mature follicles in the context of controlled ovarian stimulation [11]. The available data on FSH dose used clearly reflect the shift from agonist to antagonist protocols [12]. It has also been shown that higher implantation rates (OR 1.36) and a higher live birth rate (OR 1.33) are achieved with GnRH agonists in the context of eSET [13]. The agonist protocol carries the clinical risk of rapidly progressing ovarian hyperstimulation syndrome (OHSS), since hCG must be given for final oocyte maturation. The antagonist protocol is associated with a pronounced reduction in OHSS incidence through its use of physiological LH, which is triggered by the application of a GnRH agonist $[14,15]$. Apart from the absolute number of mature follicles, further important clinical parameters on comparison of agonist and antagonist protocols include: clinical and progressing pregnancy, abortion rate and live birth rate. To date, for these parameters no significant differences between the protocols have been demonstrated [15].

At the same time it should not be forgotten that not every patient will automatically benefit from blastocyst transfer. While a small significant advantage for live birth rate has been shown with blastocyst transfer on day 5 to 6 , a higher cumulative pregnancy rate was achieved with transfers on day 2 to 3 [16]. The authors of this study felt the result could be explained firstly by the fact that more cryotransfers took place in the classical ART cycles, and secondly because the rate of treatment discontinuations, i.e. transfer refusals, was lower [16]. eSET should be used with circumspection particularly in patients with limited ovarian reserves, i.e. poorer prognosis, since in some cases worse results are to be expected [17].

In 2012 the American Society for Reproductive Medicine (ASRM) drew the following conclusions with respect to eSET: eSET should chiefly be offered to patients with a good prognosis/recipients of donor oocytes. IVF centres should only promote eSET when patients are appropriately informed. Also, developments in embryo selection, e.g. through time-lapse techniques, should increase the use of eSET [18].

It is thus all the more important that decision-making regarding the use of DMW for a particular patient is well-informed and individualised.

Data acquisition in our study was retrospective and from a single centre so that applicability to other centres is limited. From a methodological perspective it was advantageous to compare previous and subsequent treatment cycles within individual patients, since this provided an internal control. Nevertheless this method also affected the results through only including patients who received at least one further treatment cycle. Patients who were treated by the DMW in their first cycle and who immediately fell pregnant were thus excluded. This explains the extremely low pregnancy rate of initial treatment cycles, both in the CG and EG, which accordingly was lower than the usual averages of the DIR and the study centre: patients included were almost exclusively those who did not fall pregnant in the first cycle or who had abortions.

In addition the selection process resulted in the analysis especially of older patients (CG2 $=37, \mathrm{EG} 2 / \mathrm{DMW}=36.5$ years) with a relatively higher number of cycles ( $C G=3.76, E G=3.75$ ART cycles per patient) and longer-standing wish for children $(\mathrm{CG} 2=3.65 \pm 2.28, \mathrm{EG} 2 / \mathrm{DMW}=4.96 \pm 2.36)$. In some cases previous fertility treatments had been successful. $28.5 \%$ of women in the CG2 and $22.5 \%$ in the DMW group already had children. $16 \%$ of these in the CG2 and $12.5 \%$ in the DMW group were the result of successful fertility treatment.

If one considers that our study population was one that took relatively long to fall pregnant and had a strongly negative selection, then the pregnancy and birth rates in the DMW group are very 
promising indeed, supporting the idea of greater success with a change to this procedure.

The results demonstrate that individual patients benefited from the procedure. With 61 vs. 70 actual pregnancies in the two

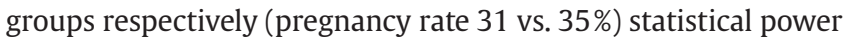
was not strong enough to show a significant benefit for EG over CG. Ultimately the study only shows trends favouring the DMW, which need to be confirmed in larger patient collectives or analyses of individual cycles.

Since in both groups we only analysed cycles involving an embryo transfer, our results are highly consistent in terms of the target parameters (embryo quality, pregnancy rate etc.).

Our collective was too small to demonstrate a reduced rate of multiple pregnancy with DMW.

In 2006 a Dutch study suggested that eSET be used in all patients if possible in order to avoid multiple pregnancy; here, however, the pregnancy rate was concurrently halved [19].

Since then it has been shown that particularly patients older than 35 who are treated with eSET and extended embryo selection, i.e. with genetic screening before embryo transfer, have significantly fewer multiple pregnancies (6.8 vs. $21 \%$ ) while also having a significantly higher live birth rate per embryo transfer (17 vs. $10.6 \%)$. For this study it was however necessary to implement relaxed policies on embryo selection, optimum culture systems, cryopreservation and aneuploidy screening of blastocysts with analysis of all 24 chromosomes [20].

It has also since been demonstrated that, unlike Double Embryo Transfer (DET), multiple pregnancy can be significantly reduced (in one study to $35 \%$ ) by the use of eSET [21].

Other study groups have also managed to show the value of eSET by demonstrating risk reduction whilst maintaining IVF success rates [22].

However, what should the approach be when a patient insists on transfer of multiple embryos despite the risk of multiple pregnancy in order to increase her chances of pregnancy within a single treatment attempt, or when the patient makes a conscious decision in favour of having twins? Patients should be empowered to make an autonomous decision through the concept of shared decision making, including comprehensive counselling on the risks of multiple pregnancy and the associated increased financial burden [23].

A shift in patient preference for twin pregnancy during the course of treatment has been described, whereby preferences usually adapt to the pregnancy situation: Whereas patients who are already pregnant tend to prefer what they are expecting (singleton or twins), before embryo transfer a greater percentage of patients show a preference for twins in order to fulfil their wish for children as soon as possible [24]. This illustrates the importance of comprehensive counselling.

In summary, it can be stated that the DMW increases the probability of pregnancy. The original intention to improve pregnancy rates while reducing the risk of twins - and associated health, personal, and financial implications - can only be realised when the number of embryos transferred is reduced.

Northern Europe, Australia and Japan are increasingly striving for the permanent establishment of eSET to reduce high rates of twins while maintaining high pregnancy rates in general. Countries such as Sweden, Finland and Belgium have demonstrated that twin pregnancies can be reduced to less than 10\% compared to otherwise generally unchanged rates of $20 \%$ in many European countries $[25,26]$. In Sweden reproductive health practitioners are only allowed to transfer single embryos, except in ex- traordinary circumstances. In Belgium the first cycle has to constitute an eSET in patients less than 36 years of age. In Finland there are not yet any statutory provisions [27].

In Germany the rule forbidding routine, intentional stockpiling of embryos remains unchanged.

The implementation of the DMW would offer German reproductive medicine practitioners the possibility of achieving higher pregnancy rates combined with reduced risk of twins, however this can only be realised if it is accepted that viable surplus embryos be frozen and stored. After thorough, individualised patient counselling and consent, taking the experiences of previous ART cycles into account, the initial intent is the transfer of one viable embryo. Since the quality of mature oocytes produced during stimulation can vary from cycle to cycle, patients must be fully informed about the need to freeze-store viable embryos in the event of more embryos being cultured than are necessary for single embryo transfer.

On this point too, the 1990 ESchG is urgently in need of reform. Only the national legislature is in a position to regulate these fundamental questions around the beginnings of human life; thus a new reproductive medicine act that is up-to-date with current medical and scientific research - however, which should not be seen as a mediator for future unrestricted embryo culture and stockpiling - is urgently required.

\section{Conclusion}

$\nabla$

The DMW offers the possibility of increasing pregnancy rates particularly in patients with adequate ovarian reserves. It should be considered when adequate numbers of oocytes can be generated, since these patients benefit significantly from the transfer of fewer embryos of the highest possible quality.

\section{Acknowledgements}

\section{$\nabla$}

We thank .05 Statistikberatung - Diplom-Psychologen Hoffmann Ostapczuk Ullrich Partnerschaftsgesellschaft, Düsseldorf, for the statistical analysis and support.

\section{Conflict of Interest}

$\nabla$

The authors declare that no conflict of interest exists.

\section{References}

1 Snick HK, Snick TS, Evers JL et al. The spontaneous pregnancy prognosis in untreated subfertile couples: the Walcheren primary care study. Hum Reprod 1997; 12: 1582-1588

2 Diedrich K, Strowitzki T, Kentenich $H$. Stand der Reproduktionsmedizin in Deutschland. Geburtsh Frauenheilk 2010; 70: 355-360

3 Bundesministerium der Justiz. Gesetz zum Schutz von Embryonen (Embryonenschutzgesetz - ESchG). Embryonenschutzgesetz vom 13. Dezember 1990 (BGBl. I S. 2746), das zuletzt durch Artikel 1 des Gesetzes vom 21. November 2011 (BGBl. I S. 2228) geändert worden ist

4 Bals-Pratsch M, Frommel M. Wandel in der Implementation des Deutschen Embryonenschutzgesetzes. J Reproduktionsmed Endokrinol 2010; 7: 87-95

5 Frommel M. Deutscher Mittelweg in der Anwendung des Embryonenschutzgesetzes (ESchG) mit einer an den aktuellen wissenschaftlichen Kenntnisstand orientierten Auslegung der für die Reproduktionsmedizin zentralen Vorschrift des $\S 1$, Abs.1, Nr. 5 ESchG. J Reproduktionsmed Endokrinol 2007; 4: 27-33 
6 Cupisti S, Muller A, Hildebrandt T et al. Culture of individually required number of 2-pronuclei-stage oocytes - patient participation in decision-making is in accordance with the aim of avoiding surplus embryo freezing. Geburtsh Frauenheilk 2014; 74: 157-160

7 Das Jahrbuch des Deutschen IVF-Registers 2013. J Reproduktionsmed Endokrinol 2014; 11: 6-51

8 Niinimaki M, Veleva Z, Martikainen $H$. Embryo quality is the main factor affecting cumulative live birth rate after elective single embryo transfer in fresh stimulation cycles. Eur J Obstet Gynecol Reprod Biol 2015; 194: 131-135

9 Thompson SM, Onwubalili N, Brown K et al. Blastocyst expansion score and trophectoderm morphology strongly predict successful clinical pregnancy and live birth following elective single embryo blastocyst transfer (eSET): a national study. J Assist Reprod Genet 2013; 30: 1577-1581

10 Sifer C, Sermondade N, Poncelet C et al. Biological predictive criteria for clinical pregnancy after elective single embryo transfer. Fertil Steril 2011; 95: 427-430

11 Shrestha D, La X, Feng HL. Comparison of different stimulation protocols used in in vitro fertilization: a review. Ann Transl Med 2015; 3: 137

12 Das Jahrbuch des Deutschen IVF-Registers 2011. J Reproduktionsmed Endokrinol 2012; 9: 453-484

13 Grow D, Kawwass JF, Kulkarni AD et al. GnRH agonist and GnRH antagonist protocols: comparison of outcomes among good-prognosis patients using national surveillance data. Reprod Biomed Online 2014; 29: 299-304

14 Devroey P, Polyzos NP, Blockeel C. An OHSS-free clinic by segmentation of IVF treatment. Hum Reprod 2011; 26: 2593-2597

15 Al-Inany HG, Yousseff MA, Aboulghar M et al. Gonadotrophin-releasing hormone antagonists for assisted reproductive technology. Cochrane Database Syst Rev 2011; 5: CD001750

16 Glujovsky D, Blake D, Farquhar C et al. Cleavage stage versus blastocyst stage embryo transfer in assisted reproductive technology. Cochrane Database Syst Rev 2012; 7: CD002118

17 Gleicher N, Kushnir VA, Barad DH. Is it time for a paradigm shift in understanding embryo selection? Reprod Biol Endocrinol 2015; 13: 3
18 Practice Committee of Society for Assisted Reproductive Technology; Practice Committee of American Society for Reproductive Medicine. Elective single-embryo transfer. Fertil Steril 2012; 97: 835-842

19 van Montfoort AP, Fiddelers AA, Janssen JM et al. In unselected patients, elective single embryo transfer prevents all multiples, but results in significantly lower pregnancy rates compared with double embryo transfer: a randomized controlled trial. Hum Reprod 2006; 21: 338 343

20 Ubaldi FM, Capalbo A, Colamaria S et al. Reduction of multiple pregnancies in the advanced maternal age population after implementation of an elective single embryo transfer policy coupled with enhanced embryo selection: pre- and post-intervention study. Hum Reprod 2015; 30: 2097-2106

21 Prados N, Quiroga R, Caligara C et al. Elective single versus double embryo transfer: live birth outcome and patient acceptance in a prospective randomised trial. Reprod Fertil Dev 2015; 27: 794-800

22 Ismail L, Mittal M, Kalu E. IVF twins: buy one get one free? J Fam Plann Reprod Health Care 2012; 38: 252-257

23 Ezugwu E, der Burg SV. Debating elective single embryo transfer after in vitro fertilization: a plea for a context-sensitive approach. Ann Med Health Sci Res 2015; 5: 1-7

24 Fiddelers AA, Nieman FH, Dumoulin JC et al. During IVF treatment patient preference shifts from singletons towards twins but only a few patients show an actual reversal of preference. Hum Reprod 2011; 26: 2092-2100

25 Kupka MS, Ferraretti AP, de Mouzon J et al.; European IVF-Monitoring Consortium, for the European Society of Human Reproduction and Embryology. Assisted reproductive technology in Europe, 2010: results generated from European registers by ESHRE†. Hum Reprod 2014; 29: 2099-2113

26 European IVF-Monitoring Consortium (EIM); European Society of Human Reproduction and Embryology (ESHRE), Kupka MS, D'Hooghe T et al. Assisted reproductive technology in Europe, 2011: results generated from European registers by ESHRE. Hum Reprod 2016; 31: 233 248

27 Harbottle S, Hughes C, Cutting R et al.; Association of Clinical Embryologists $\mathcal{E}$ The (ACE) British Fertility Society (BFS). Elective single embryo transfer: an update to UK Best Practice Guidelines. Hum Fertil (Camb) 2015; 18: 165-183 